\title{
Is home always the best and preferred place of death?
}

The current orthodoxy is that home is the best and preferred place of death for most people. Kristian Pollock questions these assumptions and calls for greater attention to improving the experience of dying in hospital and elsewhere

\author{
Kristian Pollock principal research fellow \\ Nottingham University, School of Health Sciences, Queen's Medical Centre, Nottingham NG7 2HA, UK
}

Place of death has become a key indicator of the quality of end of life care, ${ }^{12}$ underpinned by the conviction that most people would prefer to die at home. ${ }^{34}$ The institutional environment of acute hospital wards is considered an inappropriate and undesirable place in which to die, ${ }^{56}$ and there are concerns about poor quality of care..$^{7-9}$ The need to reduce costs is a further incentive for reducing deaths in hospital. ${ }^{6}{ }^{10}{ }^{11}$ However, the evidence on patients' preferences is unclear and conflicting. Regardless of preference, hospital will remain the most common place of death for the foreseeable future ${ }^{6}{ }^{12} \mathrm{Far}$ from neglecting and disregarding the hospital as a site of terminal care, much greater thought and adequate resources must be directed to enabling hospitals to provide excellent support for dying patients and their families.

\section{Is place of death a public priority?}

Public surveys commonly report that around two thirds of respondents express a preference to die at home. ${ }^{3613-15}$ However, there is considerable variation between studies. A substantial number of people do not specify a preference, ${ }^{16}$ and there is rarely an option for "it depends" or "does not matter." 17 The context and framing of the questions will shape the nature of responses, and studies vary in their design and quality. ${ }^{3}$

Public surveys, particularly among people who are young and healthy, may not accurately predict how individuals will feel when eventually confronted with their impending death. ${ }^{10}$ Notably, recent surveys indicate that although home may be selected as the preferred location, the place of death is not itself a great priority. ${ }^{10}{ }^{18}$ Survey responses rarely give an indication of how respondents anticipate or visualise their death, or what they imagine "dying at home" entails: failing to wake from sleep one day, gently fading out in front of a favourite television show, keeling over in an instant from a catastrophic heart attack, or a process of prolonged frailty and dwindling and the distress of increasing incapacity and dependency? We know little about public understanding or attitudes to death and dying: how this is envisaged, or the effect of complex contextual factors in influencing preferences. ${ }^{19}$ However, there is evidence that people often hope for a quick and unexpected - and certainly a pain free-death. ${ }^{13}$ 20-22

\section{What matters most to patients?}

Patient surveys also find that home is the most commonly expressed option, ${ }^{23}$ although often respondents do not record a preference. ${ }^{815}$ It is widely stated that many more people die in hospital than wish to do so. However, a recent systematic review concludes that the evidence for this assertion is not as strong as previously thought, particularly if changes in preference throughout an illness are recorded. ${ }^{3}$ Preferences for place of care are rarely clearly differentiated from place of death. ${ }^{15}$ When they are, preference for care at home is greater than for death at home. ${ }^{610} 1324$

As with the evidence from public surveys, it seems that although patients may specify home as their preferred place, location may not be a high priority, ${ }^{15}$ especially in comparison to freedom from distress and pain. ${ }^{410} 1822$ Qualitative evidence indicates that patient attitudes to place of death are complex, uncertain, shifting, and pragmatic. ${ }^{13} 15{ }^{20}{ }^{25-27}$ The desire to die at home tends to decrease with age and failing health ${ }^{310} 1322$ and to be weaker among patients with conditions other than cancer. ${ }^{1327}$ Carers are more likely than patients to opt for death away from home, and in retrospective accounts they often consider hospital to have been an appropriate place of death. ${ }^{3}{ }^{17} 24$

An unreflective focus on place as the determining factor of a good death distracts attention from the experience of dying. ${ }^{10} 28$ Just because a death occurred at home does not mean that it was good. The person may have been alone, inadequately supported, in pain, distressed, and fearful. ${ }^{1025}{ }^{26}$ Idealised accounts of "the good death" at home often do not recognise the reality of intractable pain and discomfort experienced by some dying patients and, for a substantial number, the sheer hard work of dying. ${ }^{29-31}$ The effort to keep death at home threatens to over-ride consideration of the struggle that may be involved for family carers or the adverse effects of social and economic disadvantage. ${ }^{6}$ 
Patients repeatedly express a desire not to impose a "burden" on their families, ${ }^{6} 10132025303233$ and a perceived advantage of hospital is that professional input can relieve the strain. ${ }^{25} 3032$ Social engagement - a core value of dying patients - and their personal integrity may be maintained more easily in institutions where staff take over care of "dirty work." 2632

The hospital may be preferred as a place of safety and effective control of symptoms, especially when pain and distress are difficult to overcome. ${ }^{13} 1734{ }^{35}$ Dying in pain is consistently reported to be the greatest concern of patients and the public. ${ }^{491036}$ However, some expect or find that pain is less well controlled at home. ${ }^{810}$

The value and emotional importance of home as a safe and private space may be degraded by its annexation as a site of hospital outreach and the invasive influx of equipment and staff that dying at home requires. ${ }^{6}{ }^{26}$ Patients and family members may have concerns about the witnessing of suffering and death and the contamination of place and memory that may be a legacy of death at home. ${ }^{30} 32-34$

\section{Constructing choice in end of life care}

The current marriage of palliative care with consumerist ideologies of patient choice promotes the view that the place, and even manner, of death and dying is largely a matter of volition. This deflects attention from the many more substantive factors constraining options, including those relating to availability of resources, the quality and availability of palliative care, the nature of the illness (particularly if not cancer), the severity and management of symptoms, the adequacy of support at home, socioeconomic circumstances, and the environment of care. ${ }^{37}{ }^{38}$ We might ask if the notion of "choice" applies to death: most people would prefer, presumably, to be not ill, not old, not dying. We know little about how patients value choice or, indeed, if they perceive themselves to be exercising choice in relation to their options for death and dying. ${ }^{39-41}$

National campaigns promote a good death as an entitlement: a matter of choice and judicious forward planning (www.

dyingmatters.org). But patients often have a more cautious and circumspect approach, suggesting a pragmatic and more realistic appraisal of uncertainty, as well as apprehension, about how they will respond to the unfathomable experience of dying. ${ }^{30} 4243$ Some patients may be undecided or uncertain and wish to relinquish the responsibility of "choice" to others. ${ }^{20}{ }^{34}$ In relation to intrinsically tragic outcomes, the obligation to choose may be experienced as risk and burden. ${ }^{40}{ }^{44} 45$ A stated preference for home may constitute a positive choice. Alternatively, it may be regarded as the least bad option. ${ }^{24} 25$

\section{Conclusion}

Focusing on place of death as the key indicator of quality in end of life care distracts attention from the experience of dying for patients and their families. ${ }^{1028}$ Evidence suggests that place of death is not the over-riding priority. Control of symptoms, especially pain, and being accompanied by loved ones are more important. ${ }^{41318}{ }^{36}$ Much greater understanding of patient and public experience and attitudes to death and dying is needed, including where this should occur. When patients wish to die at home, every effort should be made to achieve this outcome. However, until resources are in place to adequately and equitably support home deaths, the current promotion of patient choice risks raising expectations that are not realised. ${ }^{46}$ There are many reasons why patients may not wish to die at home. Death at home is not necessarily good, and just because a patient did not die at home does not necessarily mean their death occurred in the wrong place. It is important to recognise and accommodate the diversity of patient preferences for place of death, especially in the context of a cultural heterogeneity that is rarely researched or recognised. ${ }^{32} 47$

When home death becomes normatively prescribed there is a risk that it becomes increasingly difficult for patients to express alternative preferences. ${ }^{34}$ Patients may be offered choice but be expected to "choose wisely." ${ }^{(34)}$ Rather than reflecting prior and clearly articulated positions, patients' recorded preferences may become co-constructed artefacts of a discussion shaped by professional perspectives and agendas. ${ }^{27}{ }^{46}$ However well intentioned, these are inevitably influenced by pressure to achieve performance indicators for quality of care. ${ }^{27} 46$ Normalising home as the best and natural place to die promotes a sense of guilt and failure if death occurs elsewhere. ${ }^{30}$ The cultural script about death and dying risks being rewritten to promote ostensive choice as de facto obligation. Given the projected increase in institutional deaths, the hospital needs to be reinvented as a viable alternative and place of excellent care for dying patients and their families.

Contributor and sources: KP has a background in social and medical anthropology and has carried out qualitative research in a wide range of healthcare settings. This article has developed from her involvement in investigation of public attitudes to death and dying, the care of older patients dying on acute hospital wards, and the initiation of advance care planning in community care settings.

Competing interests: I have read and understood BMJ policy on declaration of interests and have no relevant interests to declare.

Provenance and peer review: Not commissioned; externally peer reviewed.

Department of Health. End of life care strategy: fourth annual report. DH, 2012.

2 Department of Health. End of life care strategy-promoting high quality care for all adults at the end of life. $\mathrm{DH}, 2008$.

3 Gomes B, Calanzani N, Gysels M, Hall S, Higginson IJ. Heterogeneity and changes in preferences for dying at home: a systematic review. BMC Palliat Care 2013;12:1-28.

Wreferences for dying at home: a systematic review. BMC Palliat Care $2013,12.1-28$. importance of place of death in the context of a good death. BMJ Supportive Palliative Care 2011:1-5.

5 Brereton L, Gardiner C, Gott M, Ingleton C, Barnes S, Carroll C. The hospital environment for end of life care of older adults and their families: an integrative review. J Adv Nurs 2012:68:981-93

6 Leadbeater C, Garber J. Dying for change. DEMOS, 2010.

7 Department of Health. More care, less pathway: a review of the Liverpool care pathway. $\mathrm{DH}, 2013$.

8 Office of National Statistics. National survey of bereaved people (VOICES), 2013. 2014 www.ons.gov.uk/ons/rel/subnational-health1/national-survey-of-bereaved-people--voices/2013/stb---national-survey-of-bereaved-people--voices-html.

9 Robinson J, Gott M, Ingleton C. Patient and family experiences of palliative care in hospital: what do we know? An integrative review. Palliat Med 2014;28:18-33.

10 Wood C, Salter J. A time and a place. Sue Ryder, 2013.

11 Hatziandreu E, Archontakis F, Daly A. The potential cost savings of greater use of home and hospice based end of life care in England. NAO, 2008.

12 Gomes B, Higginson IJ. Where people die (1974 - 2030): past trends, future projections and implications for care Palliat Med 2008;22:33-41.

13 Murtagh FE, Bausewein C, Petkova $\mathrm{H}$, et al. Understanding place of death for patients with non-malignant conditions: a systematic review. NIHR SDO Programme, 2012.

14 Gomes B, Higginson I, Calanzani N, et al. Preferences for place of death if faced with advanced cancer: a population survey in England, Flanders, Germany, Italy, the Netherlands, Portugal and Spain. Ann Oncol 2012;23:2006-15.

15 Bell C, Somogyi-Zalud E, Masaki KH. Factors associated with congruence between preferred and actual place of death. J Pain Symptom Manage 2010;39:591-604.

16 Van der Heide A, de Vogel-Voogt E, Visser A, van der Rijt CC, van der Maas PJ. Dying at home or in an institution: perspectives of Dutch physicians and bereaved relatives. Support Care Cancer 2007;15:1413-21.

17 Stajduhar KI, Allan DE Cohen SR, Heyland DK. Preferences for location of death of seriously ill hospitalized patients: perspectives from Canadian patients and their family caregivers. Palliat Med 2008;22:85-8.

18 National Council for Palliative Care. Dying matters survey. ComRes, 2014

19 Cox K, Bird L, Arthur A, et al. Public attitudes to death and dying in the UK: a review of published literature. BMJ Support Palliat Care 2012;3:37-45.

20 Gott M, Small N, Barnes S, Payne S, Seamark D. Older people's views of a good death in heart failure: implications for palliative care provision Soc Sci Med 2008;67:1113-21.

21 Emslie C, Hunt K, Watt G. "I'd rather go with a heart attack than drag on": lay images of heart disease and the problems they present for primary and secondary prevention. Coronary Health Care 2001;5:25-32. 


\section{Key messages}

Current assumptions that home is the best and preferred place of death oversimplify patient and public attitudes and preferences for death and dying

Preoccupation with dying at home as an indicator of a good death deflects attention from improving the quality of care available in other places

It is more important to focus on the experience of dying than the place of death

Hospitals will remain the place where most people die and need to provide excellent end of life care

22 Vig EK, Pearlman RA. Good and bad dying from the perspective of terminally ill men. Arch Intern Med 2004;164:977-81.

23 Gao W, Ho YK, Verne J, Glickman M, Higginson IJ. Changing patterns in place of cancer death in England: a population-based study. PLoS Med 2013;10:21001410.

24 Higginson IJ, Sen-Gupta GJA. Place of care in advanced cancer: a qualitative systematic literature review of patient preferences. J Palliat Med 2000;3:287-300.

25 Thomas C, Morris SM, Clark D. Place of death: preferences among cancer patients and their carers. Soc Sci Med 2004;58:2431-44.

26 Gott M, Seymour J, Bellamy G, Clark D, Ahmedzai SH. Older people's views about home as a place of care at the end of life. Palliat Med 2004;18:460-7.

27 Munday D, Petrova M, Dale J. Exploring preferences for place of death with terminally ill patients: qualitatative study of experiences of general practitioners and community nurses in England. BMJ 2009;338:b2391.

28 Collier A, Phillips JL, ledema R. The meaning of home at the end of life: a video-reflexive ethnography study. Palliat Med 2015;29:695-702.

29 Macdonald E. Dying in distress: the limitations of good palliative care. Commission on Assisted Dying, 2013.

30 Broom A, Kirby E. The end of life and the family: hospice patients' views on dying as relational. Soc Health IIIness 2013;35:499-513.

31 Burt J, Shipman C, Richardson A, Ream E, Addington-Hall J. The experiences of older adults in the community dying from cancer and non-cancer causes: a national survey of bereaved relatives. Age Ageing 2009;39:86-91.

32 Seymour J, Payne S, Chapman A, Holloway M. Hospice or home? Expectations of end-of-life care among white and Chinese older people in the UK. Soc Health IIIness 2007;29:872-90.

33 Chapple A, Evans J, McPherson A, Payne S. Patients with pancreatic cancer and relatives talk about preferred place of death and what influenced their preferences: a qualitative study. BMJ Support Palliat Care 2011;1:291-5.

34 Small N, Rhodes P. Too ill to talk? User involvement and palliative care. Routledge, 2000

35 Robinson J, Gott M, Gardiner C, Ingleton C. A qualitative study exploring the benefits of hobinson $\mathrm{J}$, Gott $\mathrm{M}, \mathrm{Gardiner} \mathrm{C}$, Ingleton $\mathrm{C}$. A qualitative study exploring the benefits of
hospital admissions from the perspectives of patients with palliative care needs. Palliat Med 2015;29:703-10
36 National Council for Palliative Care. Death and dying survey. London: ComRes, 2011 37 Nakamura S, Kuzuya M, Funaki Y, Matsui W, Ishiguro N. Factors influencing death at home in terminally ill cancer patients Geriatr Geront Int 2010;10:154-60.

38 Gomes B, Higginson IJ. Factors influencing death at home in terminally ill patients with cancer: systematic review. BMJ 2006;332:515-21.

39 Salmon P, Hall GM. Patient empowerment or the emperor's new clothes. J R Soc Med 2004;97:53-6.

40 Drought TS, Koenig BA. Choice in end-of-life decision making: researching fact or fiction? Gerontologist 2002;42:114-28

41 Borgstrom E. Planning for an (un)certain future: choice within English end-of-life care. Current Sociol 2015 Jul 13. [Epub ahead of print.]

42 Munday D, Dale J, Murray SA. Choice and place of death: individual preferences, uncertainty, and the availablity of care. J R Soc Med 2007;100:211-7.

43 Difficult conversations with dying patients and their families. Marie Curie Cancer Care, 2014.

44 Botti S, McGill AL. When choosing is not deciding: the effect of perceived responsibility on satisfaction. J Consumer Res 2006;33:211-9.

45 Botti S, Orfali K, lyengar SS. Tragic choices: autonomy and emotional responses to medical decisions. J Consumer Res 2009;36:337-52.

46 Pollock K, Wilson E. Care and communication between health professionals and patients affected by severe or chronic illness in community care settings: a qualitative study of care at the end of life. Health Serv Delivery Res 2015;3:31.

47 Calanzani N, Koffman J, Higginson IJ. Palliative care and end of life care for black, Asian and minority ethnic groups in the UK. King's College, 2013.

Accepted: 11 August 2015

Cite this as: BMJ 2015;351:h4855

(C) BMJ Publishing Group Ltd 2015 